\title{
How Aligned Are We? Assessment Procedures and Practices Between Early Childhood and Early Intervention
}

\author{
Toia Caulcutt and Vanessa Paki \\ University of Waikato
}

\begin{abstract}
Early intervention and early childhood share a unique space in our early years education in Aotearoa/New Zealand. The assessment practices of the two are distinctively different and specific to each discipline. As assessment is a powerful agent for change and responsiveness to learners this article will unpack the reasoning behind these differences and consider the possibility of addressing a possible alignment through the early childhood curriculum Te Whāriki (Ministry of Education, 1996).
\end{abstract}

\section{Practice paper}

Keywords: Assessment, curriculum, early childhood education, early intervention

\section{INTRODUCTION}

Planning for learning opportunities for children is a fundamental principle unique to all educational domains. The pursuit of excellence has led us to the path of assessment; of the child, the service, educational delivery and most recently ourselves as practitioners to ensure we meet the needs of all learners. Within early childhood education (ECE), the national curriculum Te Whāriki (Ministry of Education, 1996) supports a proactive approach with teaching supported by ongoing assessment, planning and reflection, in which the educator is a central key to the success of the child. Te Whäriki is also vital in the assessment practices of early intervention (EI) services across Aotearoa/ New Zealand. However, with EI linked firmly to accountability measures and then to resource allocation (Ministry of Education, 2001), the assessment process encompasses a balance between individual need, allocation of resources and professional assistance. This variance in assessment practice and procedures between ECE and El has formed the basis for conflicting perspectives. In particular, how do we determine what is best for children with special needs in early childhood services? In this paper we will examine the assessment practices of both ECE and EI. We will explore assessment approaches, highlight similarities and differences, and finally look into possibilities for a realignment of assessment for both disciplines.

\begin{abstract}
ASSESSMENT PURPOSES AND PROCEDURES
Traditional assessment processes in ECE outside Aotearoa/New Zealand have been significantly influenced by developmentally appropriate practices (DAP), which is an organised system of measuring children's development from birth onwards (Aldwinckle, 2001; Hestenes \& Carroll, 2000; Jambunathan \& Counselman, 2001; Linder, 1993; Mahoney \& Wheelen, 1999). This system clearly defines a view of typical child development, which has stimulated international debate because of its monocultural, sequential perspective, and its sole focus on levels of developmental attainment (Aldwinckle, 2001). Aldwinckle (2001) also criticised DAP by questioning the ethnocentricity in the assessments' view of what is typical child development.
\end{abstract}

Early childhood pedagogy in Aotearoa/New Zealand is unique in design, supported by a holistic bicultural curriculum, and using a multifaceted approach to assessment (Claxton \& Carr, 2004). Te Whāriki (Ministry of Education, 1996) is founded upon four unique principles: kotahitanga - holistic development; whakamana - empowerment; whānau tangata - family and community, and ngā hononga - relationships. These principles are in turn supported by five core curriculum strands, wellbeing, belonging, contribution, communication and exploration (Ministry of Education, 1996). In Aotearoa/New Zealand, Te Whāriki supports a collaborative perspective to learning, based on the work of Bronfenbrenner (1979). Learning is viewed as a process of interactions between the learner and their immediate environments, including adults, peers, communities of learning and general societal beliefs and values which influence the learner (Claiborne \& Drewery, 2010). This view is equally supported in a bicultural context by theorists such as Pere (1991) and Durie (1993) where, from a Māori perspective, learning is also in conjunction with complex, yet inclusive, ideologies. These ideologies include unique, non-tangible aspects such as wairua - a spiritual dimension - and validate its place in assessment and learning processes not only for Māori children, but all learners (Ministry of Education, 1996). It is the inclusion of the abstract that makes the national ECE curriculum, Te Whāriki, unique. 
Te Whāriki is also quite pivotal in its recognition that learning does not necessarily follow a pre-organised chronological pattern (Ministry of Education, 1996). Te Whāriki recognises that learning, although on a continuum, is not necessarily predictable and also acknowledges that learning is dependent upon the environment and what we as adults contribute to it. A significant principle is ngā hononga (relationships), through which "children learn through responsive and reciprocal relationships with people places and things" (Ministry of Education, 1996, p. 43). From this lens we were able to acknowledge that children require adult assistance to access their learning and follow their own interests (Hatherly \& Sands, 2002). Early childhood pedagogy in Aotearoa/New Zealand has progressed since Te Whāriki was first published in 1996. We have moved from traditional planning to a model of noticing, recognising and responding, then documenting (Claxton \& Carr, 2004; Carr, May \& Podmore, 1998). A key shift here is less preplanned activity, and instead opportunities for children to self-direct their own interests, and for practitioners to provide co-constructed environments which support these interests (Hatherly \& Sands, 2002).

To support this new perspective, Carr (1998; 2001) developed learning stories in a project with teachers in five early childhood services. This is an assessment tool used in early childhood education services and in which the core curriculum strands are integrated into the assessment, supported by key learning dispositions that may be pivotal to a child's learning. The curriculum principles are also guiding principles for the assessment process used by early childhood teachers (Ministry of Education, 1996). The learning stories approach to assessment is also referred to by Dunn (2004) as a formative assessment practice, as opposed to summative assessment. Dunn (2004) elaborates further, stating that formative assessment provides the learner with an ongoing journey, learning opportunities available are recognised, and additional supports are recommended. Hatherly and Sands (2002) also argue that following children's interests, using assessment, provides the learner with selffulfilment and confidence, some core outcomes that are often neglected in traditional assessments. Most importantly here is that episodes of learning can be revisited in follow-up assessments, hence learning is on a continuum rather than assessing learning as a slice of time in a child's life. Another key shift for early childhood teachers has been the inclusion of various perspectives in assessment (Carr, May, \& Podmore, 1998). By pulling together the various lenses on assessment for learning we can evaluate the learning opportunities as a community, rather than as an individual with any single narrow perspective. With this viewpoint in mind, early childhood teachers are able to use learning stories as a method of building partnerships with parents (Hatherly \& Sands, 2002), and include and validate the learners' perspective too.

Essential to the practice of learning stories as a form of assessment is that early childhood teachers view children's assessments as a complex, yet collaborative process where the teachers are enablers. Learning stories place the responsibility for children's learning on the environment and opportunities provided by educators. This form of assessment also places emphasis on what the learner is capable of, and what they may be capable of with additional support provided by the educator (Carr et al., 1998). This proactive, responsive form of assessment includes reflection on "where to next".

\section{EARLY INTERVENTION AND ASSESSMENT}

\section{Early intervention services}

Early intervention, as a discipline, has carved a subtle yet distinctive path from that of early childhood teachers. Intervention teachers focus primarily on an individual child's global development highlighting areas of need throughout their time with the service (Ministry of Education, 2004). In Aotearoa/New Zealand there is a diverse range of early intervention services, ranging from government funded and operated, to private, trust, or organisationally owned. Regardless of the management, services here in Aotearoa/New Zealand are funded by similar sources - most through government funding, from education and health sectors. Some organisations also continue to fundraise privately to support their service. Some services offer unique forms of service delivery, including health orientation, total language immersion, or Māori for Māori focused (Ministry of Education, 2004). Philosophical underpinnings are unique to each organisation and their reasons for being founded.

\section{Developmentally appropriate practices}

Originally, early intervention as a discipline focused solely on the teaching of skills to children who were intellectually disabled (Fraser, Moltzen \& Ryba, 2005). This form of intervention was deeply based in a medical discourse, viewing children as in need of "fixing" (Neilson, 2005). This medical discourse highlights deficits and initially formed the basis of a focus core for early intervention practice (Dunn, 2004). Although there have been significant shifts in the field of disability, of particular interest is the shift from a medical discourse to a rights discourse (Neilson, 2005), 
the question remains - how much has this shift in inclusive thinking evolved into the assessment practices and procedures of early intervention teachers?

Early intervention teachers have faced similar paths to those in the early childhood sector regarding assessment. Like early childhood practitioners, early intervention teachers have also been strongly influenced by the founding assessment approach of Developmentally Appropriate Practices (DAP) (Huffman \& Speer, 2000). Montessori's original work in the early 1900s (Roopnarine \& Johnson, 1993) supported the medical discourse in her work with young children with disabilities where the focus was on specific skill acquisition. Dunn (2004) referred to this as the "test and teach" method, from which came the development of standardised criterion-based assessment.

Standardised criterion-based assessments have been used as an assessment approach across all early intervention providers. These forms of assessment are characterised by their focus on specific skills, which have been paralleled with a chronological measurement (Anderson, 2004; Dunn, 2004; Macy, Bricker, \& Squires, 2005; Mahoney \& Wheeden, 1999). These forms of assessment have been useful to early intervention teachers as they clearly define the child's needs, which then correspond with the design of service delivery and required resources (Bricker, 1995; Macy et al., 2005). Various standardised criterion-based assessments have been developed, some being more specific to chronological and developmental stages, for example the tool Developmental Programming for Infants and Young Children (Schafer \& Moersch, 1981). Other resources focus more specifically on targeted areas, for example, Transdisciplinary Play-based Intervention: Guidelines for Developing a Meaningful Curriculum for Young Children (Linder, 1993), which concentrates on children's overall sub-skill development. However, traditional practice in early intervention is the use of several standardised assessments so the early intervention teachers can cross-reference and gain a deeper understanding of the child being assessed (Bricker, 1995; Ministry of Education, 2004).

\section{Funding allocation processes}

A critical factor to consider is the allocation of government resources based on individual level of need, which is where a standardised criterion assessment has its advantages for early intervention teachers. Macy et al., (2005) discuss the importance of remaining impartial during assessments, which validates the child's eligibility to access resources. The Ministry of Education (2004) also supports this view with policies and criteria to support early intervention services. The Ministry of Education has several policies that determine funding allocation to early intervention services, which in turn directly impact the assessment practices and procedures of early intervention teachers in Aotearoa/New Zealand. The Statement of Intent (Ministry of Education, 2007) endorses a commitment to early intervention. Assessment must have a clear process, with key outcomes attached. These processes include how the assessments will be used to determine eligibility, and the importance of using formal assessment tools, or standardised criterion-based assessments (Ministry of Education, 2001). The assessment phase should incorporate a range of material gathered, including interviews with staff at the early childhood education service, parental input, paraprofessional reports and observations. However, the core material used to determine resource allocation is the standardised assessment (Bricker, 1995; Macy et al., 2005; Ministry of Education, 2001).

\section{SIMILARITIES AND DIFFERENCES}

A key similarity between the two disciplines, EI and $\mathrm{ECE}$, is that both gather assessment information in order to learn more about the child. Both early childhood and early intervention acknowledge the importance of noticing learning as it occurs, and recognising its significance (Dunn, 2004). Both disciplines also recognise the significance of responding to that interest or learning, however differences can often determine how the response is carried out.

During the assessment phase, early intervention teachers are attempting to gather all perspectives, however their fundamental objective is to assess the child's needs in terms of their organisation's resource criteria (Bricker, 1995; Linder, 1997) because this determines their ongoing support. This form of assessment tends to focus on a slice of time, when the child is formally assessed and measured against a formal assessment tool. The measurement documents what the children are capable or not capable of at this time and in these circumstances (Dunn, 2004). Hence, their response is skill-acquisition based, not interestbased. Bagnato (2005) refers to this as being "fieldvalidated".

Early childhood teachers tend to focus on what children are currently interested in (Carr, 2001; Carr et al., 1998; Hatherly \& Sands, 2002) and recognise that learning dispositions play a significant part in their long-term learning. The use of learning stories assessment has encouraged a proactive discourse and highlights what the child is capable of, given a facilitating environment. 
Sociocultural assessment focuses on the adults ${ }^{\prime}$ role in ensuring a co-constructed learning environment and also provides the learner and their families/whānau with a voice.

Another key point of difference is that early intervention seems to be more determined by international standards rather than looking at what we have developed locally within Aotearoa/New Zealand. Unlike the Early Childhood community, early intervention assessment is still dominated by internationally designed standardised tools which, we would argue, are not entirely aligned with contemporary early childhood culture. We do not have an early intervention assessment tool that connects to the national curriculum $T e$ Whāriki (Ministry of Education, 1996), and few early intervention tools work in unison with current early childhood practices. The bicultural nature of the curriculum is obviously not present in any internationally constructed assessment tools and this aspect of practice is left to the experiences and knowledge of early intervention teachers.

\section{Realignment}

We have in this paper signalled the possibilities of a realignment of ECE and EI, which ideally could function in a more cohesive manner. While we would not advocate losing criterion-based assessment, we would certainly argue a case for the presence of some other formative assessment practices somewhere in documentation and delivery. Multiple lenses can provide a richness and depth that a singular lens cannot. This would also allow for families/whānau to have a say in their child's assessment. This could also provide the opportunity for families/whānau to have their cultural beliefs validated in an assessment procedure.

One concern is that while learning stories is an assessment practice used in early childhood and is inclusive of Te Whāriki (Ministry of Education, 1996), the approach does not have the adequate measurement competencies required by the Ministry of Education to be deemed a formal assessment tool. What we suggest is that this system be adapted to suit both early childhood and early intervention specifically, with the key focus being on the assessment itself and the associated processes and procedures. Research by Lepper, Williamson and Cullen (2003) began to explore the possibilities of such a model, but little research has been conducted to investigate what assessment we as a country would like to develop with regards to early intervention. Forthcoming work by Dunn will be helpful. And of particular interest would be the view we hold nationally with regards to inclusion, valuing difference, children with special needs, their families and how we should deliver specialist assistance. It is important that both disciplines are working more in unison and are speaking the same language to each other and with families/ whānau. There are some key questions that we believe we should be asking of ourselves as an early childhood community. How should we assess tamariki/children? How do we validate the cultural heritage of our tamariki in our assessments? How are parents, family and whānau perspectives acknowledged, valued and supported?

Internationally there has been a push for reevaluation of our values as a community, particularity with regards to people with disabilities and supporting a rights discourse (Neilson, 2005). Van der Heyden (2005) supports this initiative by asking a question of the early childhood and early intervention communities: Should we be measuring what is possible rather than what is currently present? McLean (2005) also agrees with this perspective - that we should be looking at how we determine eligibility and why are we so focused on a measuring stick. McLean (2005) suggests that we should be more focused on a progressive form of assessment in early intervention. In order to do so we would require some extensive research into the field of early intervention in the context of Aotearoa/New Zealand.

In Aotearoa/New Zealand the use of learning stories provides a forward thinking assessment tool specifically designed with relevance to our Te Whāriki (Ministry of Education, 1996). Assessment tools which have been developed to support the quality of learning stories include Kei Tua o te Pae (Ministry of Education, 2004/2007/2009) and Te Whatu Pokeka (Ministry of Education, 2010). Surely we could use these resources to realign the two disciplines and to respond to the New Zealand context. With adequate support from the Ministry of Education, and research into alignments of early childhood and early intervention communities we could continue on this proactive search for quality for all children.

In considering a possible bridge between early intervention and early childhood, a critical issue is the bicultural nature of Te Whāriki (Ministry of Education, 1996) and the importance of responsiveness to the New Zealand context. Te Whäriki recognises the dual heritages of Aotearoa/ New Zealand, and the importance of diversity and social justice. Development is perceived as occurring in multiple contexts, is formative and holistic, and values the rich cultural fabric of each family and the influence this has on the child's development. This recognition is particularly critical to the assessment process as it illuminates 
the unique setting and cultural capital of each learner. It also situates the child within a rich, wide environment and context that is reciprocal and unique as the learners themselves. By viewing children in this way we will recognise the strengths of their context and richness of their families which is crucial to both early intervention and early childhood.

We would recommend further exploration of these ideas and in particular a closer look into the outcomes and possibilities for assessment procedures in early intervention for Māori learners.

\section{REFERENCES}

Aldwinckle, M. (2001). The DAP debate: Are we throwing the baby out with the bath water? Australian Journal of Early Childhood, 26(2), 36-39.

Anderson, L. (2004). Appropriate and inappropriate interpretation and use of test scores in early intervention. Journal of Early Intervention, 27(1), 55-68.

Bagnato, S. (2005). The authentic alternative for assessment in early intervention: An emerging evidence-based practice. Journal of Early Intervention, 28(1), 17-23.

Bricker, D, (1995). The challenge of inclusion. Journal of Early Intervention, 19(3), 179-194.

Bronfenbrenner, U. (1979). The ecology of human development: Experiments by nature and design. Cambridge, MA: Harvard University Press.

Carr, M. (1998). Learning Stories. Reading no. 2. Assessing young children's learning in early childhood settings. Support booklet and three videos. Wellington, New Zealand: NZCER.

Carr, M. (2001). Assessment in early childhood settings: Learning stories. London: Paul Chapman Publishing.

Carr, M., May, H., \& Podmore, V. (1998, September). Learning and teaching stories: New approaches to assessment and evaluation in relation to Te Whaariki. Symposium for 8th European Conference on Quality in Early Childhood Settings, Santiago de Compostela, Spain.

Claiborne, L. Bird, \& Drewery, W. (2010). Human development: Family, Place, Culture (3rd ed.). Sydney: McGraw-Hill.

Claxton, G., \& Carr, M. (2004). A framework for teaching learning: The dynamics of disposition. Early Years, 24(1), 87-97.

Dunn, L. (2004). Developmental assessment and learning stories in inclusive early intervention programmes: Two constructs in one context. New Zealand Research in Early Childhood Education, 7, 119-133.
Durie, M. H. (1993). Māori and the State: Professional and Ethical Implications for a Bicultural Public Service. Conference Proceedings of the Public Service Senior Management Conference, State Services Commission, Wellington, pp. 23-35.

Fraser, D., Moltzen, R., \& Ryba, K. (Eds.). (2005). Learners with special needs in Aotearoa New Zealand (3rd ed.). Southbank, Victoria: Thomson Dunmore Press.

Hatherly, A., \& Sands, L. (2002). So what is different about Learning Stories? The first years: Nga tau tuatali. New Zealand Journal of Infant and Toddler Education 4(1), 8-12.

Hestenes, L., \& Carroll, D. (2000). The play interactions of young children with and without disabilities: individual and environmental influences. Early Childhood Research Quarterly, 15(2), 229-246.

Huffman, L., \& Speer, P. (2000). Academic performance among at-risk children: The role of developmentally appropriate practices. Early Childhood Research Quarterly, 15(2), 167-184.

Jambunathan, S., \& Counselman, K. (2001). Relationship between developmentally appropriate beliefs and practices of pre-service teachers. Journal of Early Childhood Teacher Education, 22(2), 103-108.

Lepper, C., Williamson D., \& Cullen, J. (2003) Professional development to support collaborative assessment. Early Education 33, 19-88.

Linder, T. (1993). Transdisciplinary play-based intervention: Guidelines for developing a meaningful curriculum for young children. Baltimore, MD: Paul H. Brookes.

Macy, M. G., Bricker, D. D., \& Squires, J. K. (2005). Validity and reliability of a curriculum-based assessment approach to determine eligibility for Part C services. Journal of Early Intervention, 28(1), 1-16.

Mahoney, G., \& Wheeden, C. A. (1999). The effect of teacher style on interactive engagement of preschool-aged children with special learning needs. Early Childhood Research Quarterly, 14(1), 51-68.

McLean, M. (2005). Using curriculum-based assessment to determine eligibility: Time for a paradigm shift? Journal of Early Intervention, 28 (1), 23-28

Ministry of Education (1996). Te whāriki: He whāriki matauranga mō n ngā tamariki ō Aotearoa. Early childhood curriculum. Wellington, New Zealand: Learning Media.

Ministry of Education. (2001). Statement of intent 2001-2006. Wellington, New Zealand: Author. 
Ministry of Education. (2004/2007/2009). Kei Tua o te Pae. Assessment for Learning: Early Childhood Exemplars. Wellington, New Zealand: Learning Media.

Ministry of Education. (2004). Professional Practice in Special Education. Wellington, New Zealand: Learning Media.

Ministry of Education. (2007). Statement of intent 2007-2012. Wellington, New Zealand: Author.

Ministry of Education (2009) Te Whatu Pōkeka. Kaupapa Māori Assessment for Learning: Early Childhood Exemplars. Wellington, New Zealand: Learning Media.

Neilson, W. (2005). Disability: Attitudes, history and discourses. In D. Fraser, R Moltzen \& K. Ryba (Eds.), Learners with special needs in Aotearoa New Zealand (3rd ed., pp. 9-21). Southbank, Victoria: Thomson Dunmore Press.

Odom, S. (2002). Narrowing the question: Social integration and characteristics of children with disabilities in inclusion settings. Early Childhood Research Quarterly, 17(2), 16-170.

Pere, R. (1991) Te Wheke: A Celebration of Infinite Wisdom. Gisborne, New Zealand: Ao Ako Global Learning.

Roopnarine, J., \& Johnson, J. (Eds.). (1993). Approaches to early childhood education (2nd ed.). New York: MacMillan.

Schafer, D. S., \& Moersch, M. S. (1981). Developmental programming for infants and young children (3rd ed., rev.). Ann Arbor, MI: University of Michigan Press.

Van der Heyden, A. (2005). Intervention-driven assessment practices in early childhood/early intervention: Measuring what is possible rather than what is present. Journal of Early Intervention, 28(1), 28-34.

\section{AUTHORS' PROFILES}

\section{Toia Caulcutt}

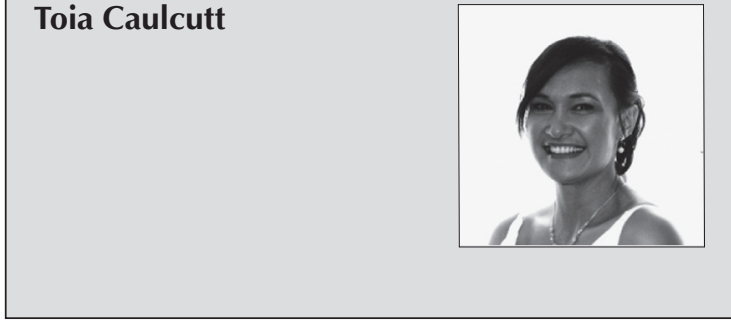

Toia Caulcutt lectures in the Early Childhood and Ki Taiao Programme at the Faculty of Education, University of Waikato. Toia has an interest in Inclusive Education, Early Intervention, Matauranga Māori and Assessment.

EMAIL

caulcutt@waikato.ac.nz

\section{Vanessa Paki}

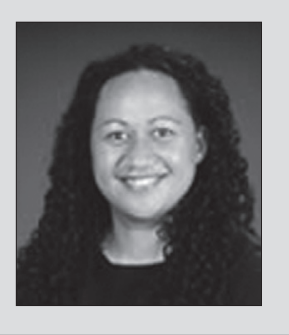

Vanessa Paki lectures in the Early Childhood and Ki Taiao Programme at the Faculty of Education, University of Waikato. Vanessa has an interest in inclusion, Matauranga Māori, assessment, transition in the early years, and philosophy.

EMAIL

paki@waikato.ac.nz 